\title{
Nuevo terminus augustalis de Valencia del Ventoso (Badajoz, España), que confirma la prefectura emeritense meridional
}

\section{New terminus augustalis from Valencia del Ventoso (Badajoz, Spain) that confirms southern prefecture of Augusta Emerita}

\author{
PABLO PANIEGO DÍAZ \\ Instituto de Arqueología-Mérida \\ (CSIC-Junta de Extremadura) \\ Plaza de España, 15. 06800 Mérida (Badajoz) \\ pablo.paniego@iam.csic.es \\ https://orcid.org/0000-0002-6218-0938
}

\author{
JOSÉ LUIS RAMÍREZ SÁDABA \\ Catedrático de Historia Antigua de la \\ Universidad de Cantabria. Jubilado \\ jose.ramirez@unican.es \\ https://orcid.org/00oo-0001-7774-7952
}

\author{
NICOLÁS GUILLÉN VÁZQUEZ \\ Investigador independiente \\ nicoguiva@outlook.es \\ https://orcid.org/o0oo-0001-7963-3852
}

\section{Resumen}

A mediados del siglo XIX fue descubierto en Solaparza, Valencia del Ventoso (Badajoz, España), un terminus augustalis de la Colonia Augusta Emerita. Recientemente, se ha encontrado un cipo de granito en la fuente de El Cañuelo, también en Valencia del Ventoso, cuya lectura, a pesar de su estado fragmentario, parece igual al localizado hace más de 150 años en Solaparza. La interpretación del nuevo epígrafe como un nuevo termino augustal, confirma que ambos termini, situados $20 \mathrm{~km}$ al sur del límite de la pertica emeritensis, delimitan una de las tres prefecturas asignadas a la Colonia Augusta Emerita.

Palabras clave: término augustal, praefectura emeritensis, Augusta Emerita, El Cañuelo

\section{Abstract}

A terminus augustalis from Colonia Augusta Emerita was discovered in the mid-19 ${ }^{\text {th }}$ century in Solaparza (Valencia del Ventoso, Badajoz, Spain). Recently, a granite block with an inscription has been found in El Cañuelo fountain (also in Valencia del Ventoso) whose reading, despite its fragmentary state, seems to be the same as the one located more than 150 years ago in Solaparza. The new epigraph interpretation as a new terminus augustalis confirms that both termini, located $20 \mathrm{~km}$ south of the pertica emeritensis boundary, define one of the three praefecturae assigned to Colonia Augusta Emerita.

Key words: Augustan boundary-stone, praefectura emeritensis, Augusta Emerita, El Cañuelo 
El terminus augustal de Valencia del Ventoso (HEP 5 , 1995, I15; $A E$, 1993, 917b; $A E$, 2013, 786), conservado en el MAP de Badajoz (Salas et alii, I997: 64-65), se ha relacionado con la existencia de una praefectura, dada la imposibilidad de que se trate del límite meridional del ager emeritensium (Cordero, 20IO; 20I3: 80-8I), al enclavarse en plena Baeturia Celticorum (figura I) (García Iglesias, 197I). Cabe preguntarse entonces por las razones de la posible asignación de una prefectura en este territorio, así como sus límites y extensión.

Partiendo del epígrafe de Montemolín (HEp 5, 1995, I09), Canto sostiene que en el sector oriental de la cuenca del Ardila se estableció una praefectura de Augusta Emerita, concretamente la denominada Mullicensis, que relaciona con un topónimo céltico (1989: I76-177) ${ }^{1}$. Esta prefectura, que tendría en Montemolín uno de sus límites, se ubicaba en una zona especialmente feraz y cerca de donde dicha autora sitúa una de las canteras de mármol más importantes de la región en época romana (1977-I978: I78-179). Ambos recursos, tierras y mármol, hacen que Rodríguez Martín (2008-2009: 445) suscriba la hipótesis de una prefectura emeritense en esta zona, la cual se extendería desde Alconera y Los Santos de Maimona hasta, quizá, Montemolín, en línea con lo defendido por Canto (I989, fig. I), quien plantea un extenso territorio que abarca desde Burguillos del Cerro hasta el hito Montemolín, marcando el de Valencia del Ventoso uno de sus límites meridionales. Sin embargo, dicha idea parece quedar matizada cuando sostiene que ambos termini delimitan los vértices oriental y occidental (1989: 188-ı9o; 1997: 132) o cuando reconoce que, aunque es posible que en Valencia del Ventoso pudiera hallarse la prefectura Mullicensis, se decanta por una localización más oriental para esta, al noreste de Monesterio (Canto, 1997: 19I, nota 132; Kerner, 2013: 43).

Todas estas propuestas quedan invalidadas, una vez aclarado el equívoco originado por la publicación de Fita, por sendas publicaciones paralelas hechas por González Fernández (1996) y Ramírez Sádaba (1993), recogidas en $A E$, I993, 917a y b y en $H E p$ 5, 1995:

1 Identificación que refutó Ramírez Sádaba (1993:305) por razones geográficas y lingüísticas.
- En el no rog se recoge la inscripción, procedente de Montemolín, que Fita leyó terminus aug(ustalis) para(torum) col(oniae) A(ugustae) Emeritae y que González Fernández, previa la preceptiva autopsia, leyó: - - - - - / [- - -f]am[ini ? - - -/- - Caesar $]$ is $\cdot \operatorname{Aug}($ usti) $\cdot$ pra[fecto--- ]/3[---co](oni-) - Aug(ust-) - Eme[rit- - - -], demostrando que se trata de un epígrafe honorífico.

- El no II5, recoge la edición de Ramírez Sádaba (que ignoraba la publicación referida en el $n^{\circ}$ Iog), del terminus de Solaparra/Sola Parza, procedente de Valencia del Ventoso, donde se lee terminus augustalis finis emeritensium.

En el catálogo de Cortés Bárcena (2013: 75-78), recientemente editado, de igual forma se registra como terminus exclusivamente el de Valencia del Ventoso, desechando como tal el de Montemolín.

Retomando la cuestión de la prefectura, Berrocal-Rangel (2004: 167-I74) también defiende su existencia, planteando que en ella pudieron asentarse los auxiliares licenciados. Esta se ubicaría al este de la cuenca del Ardila junto a la confluencia con el Bodión, siendo su límite meridional el hito de Valencia del Ventoso. Dicho autor relaciona este territorio con el bosque sagrado de Feronia (Agenio Úrbico, Th., 37). Sin embargo, es communis opinio que este bosque sagrado estaba en los alrededores de Santa Lucía del Trampal (Alcuéscar, Cáceres), como sostiene M.P. García-Bellido (200I: 53-71).

En definitiva, corregida la lectura del epígrafe de Montemolín comprobando que ni hay prata ni delimitación alguna, es, por el contrario, evidente la función del terminus aparecido en los Altos de Solaparza o Solaparra (Valencia del Ventoso), que Madoz (1847, XV: 454) describió así: «[...] en la cord. llamada los Altos de sola parza, se encontró hace pocos años una piedra cuadrangular de 5/4 de alto con esta inscripción: Terminus augustalis finis emeritensium», lo cual coincide con la lectura realizada por J.A. Barrientos, el primero, cronológicamente hablando, que dio noticias del epígrafe de Valencia del Ventoso (Gimeno y Ramírez Sádaba, I998: 156), y con la realizada por Ramírez Sádaba (1993) tras su estudio.

La zona del hallazgo destaca dentro de la cuenca del Ardila por su feracidad, pues esta discreta elevación 


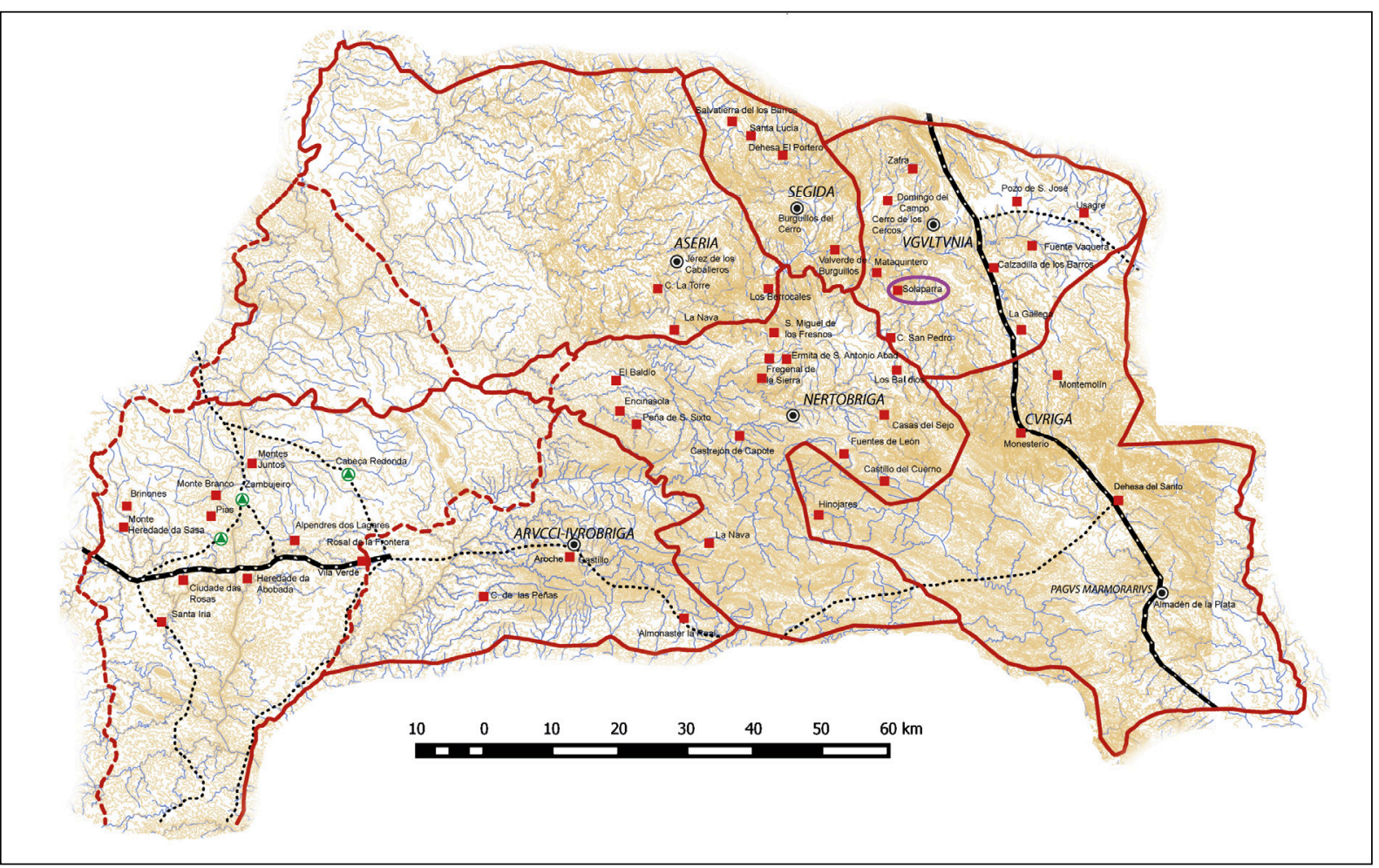

Figura 1. Mapa de la Beturia Céltica elaborado para la reedición del CIL II. Conventus Hispalensis: Norte, señalando el lugar del hallazgo del terminus de Solaparra/Solaparza

Figure 1. Baeturia Celticorum map elaborated for the CIL II reedition. Conventus Hispalensis: North, indicating the Solaparra/Solaparza terminus finding place

se encuentra en el límite occidental de un manchón de tierras rojas similar a la existente en Tierra de Barros, que constituye gran parte del ager emeritensium.

\section{El terminus de El Cañuelo}

A este documento, ya conocido, hemos de sumar otro probable fragmento de terminus documentado en el mismo municipio $^{2}$ (figura 2). Es este un bloque de granito fragmentado, de $(36) \times(47) \times 22 \mathrm{~cm}$, reutilizado en la construcción de la fuente de El Cañuelo, donde se constatan otros restos antiguos en su fábrica. El elemento aquí descrito (figura 3) se sitúa en su cara posterior, si se utiliza de referencia el camino, en posición vertical. En él se puede leer:

\section{TERM}

ISFINI
La primera letra conservada, que hemos interpretado como una $\mathrm{T}$, conserva únicamente el asta vertical, mientras que el resto de letras son legibles con cierta claridad a pesar de la erosión del monumento y miden $9 \mathrm{~cm}$. Aunque el cipo se encuentra rodeado de cemento en todas sus aristas, dificultando delimitar la pieza, posiblemente tuviera solamente dos líneas, a diferencia del procedente de Solaparza.

Dada la erosión del epígrafe, se decidió llevar a cabo un tratamiento digital con el fin de potenciar su visualización. Este proceso consistió en la realización de un modelo fotogramétrico con el software Agisoft Metashape, que fue posteriormente tratado con Blender (figura 4).

Si el texto fuera el mismo que tiene el terminus publicado por Ramírez Sádaba (1993) habría que restituir (si ambas líneas tenían el mismo número de letras):

TERMINVS AVGVSTA

LIS FINIS EMERITENS(ium) 


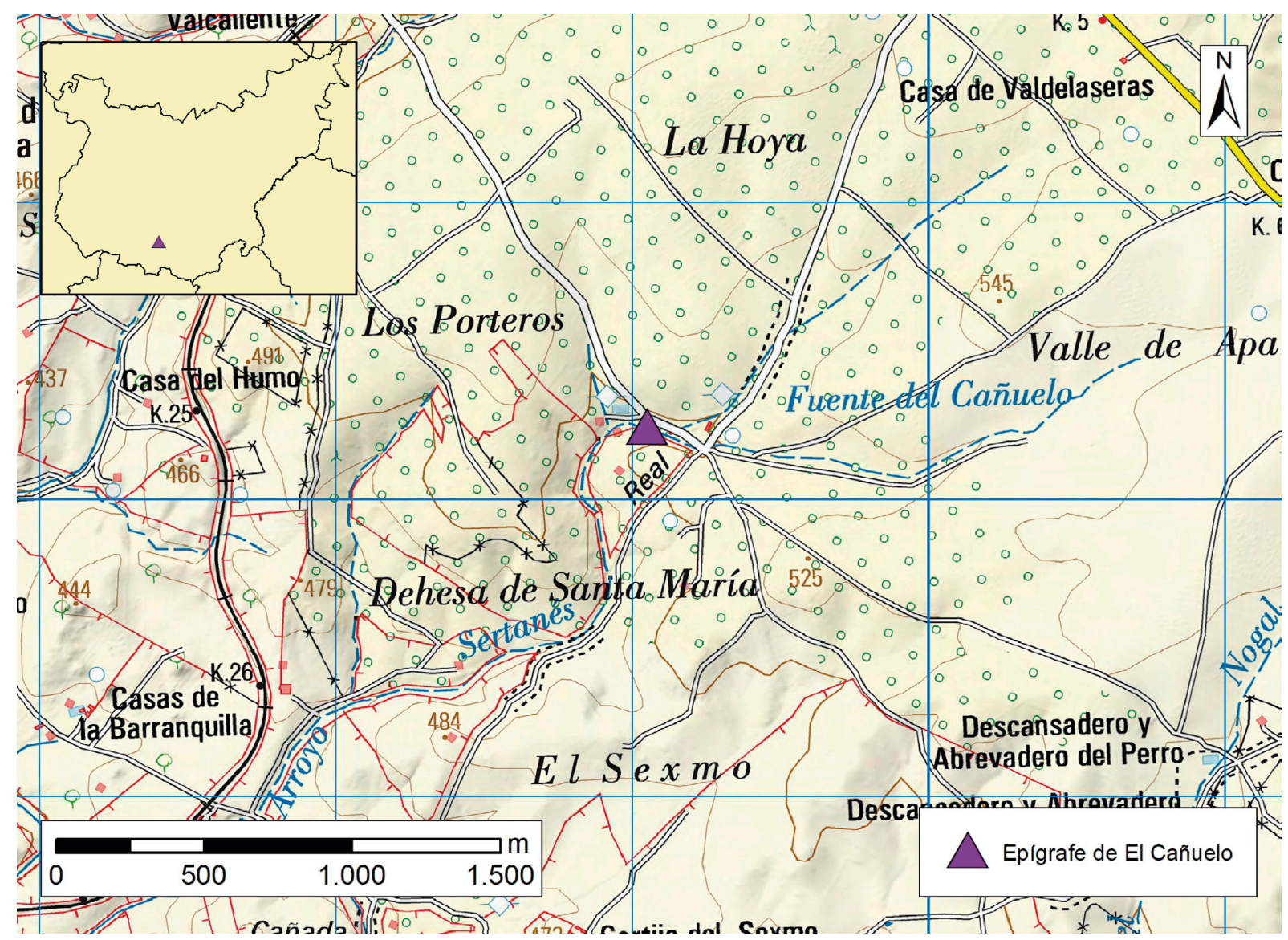

Figura 2. Plano general del lugar del hallazgo del epígrafe de El Cañuelo

Figure 2. El Cañuelo epigraph finding location general map

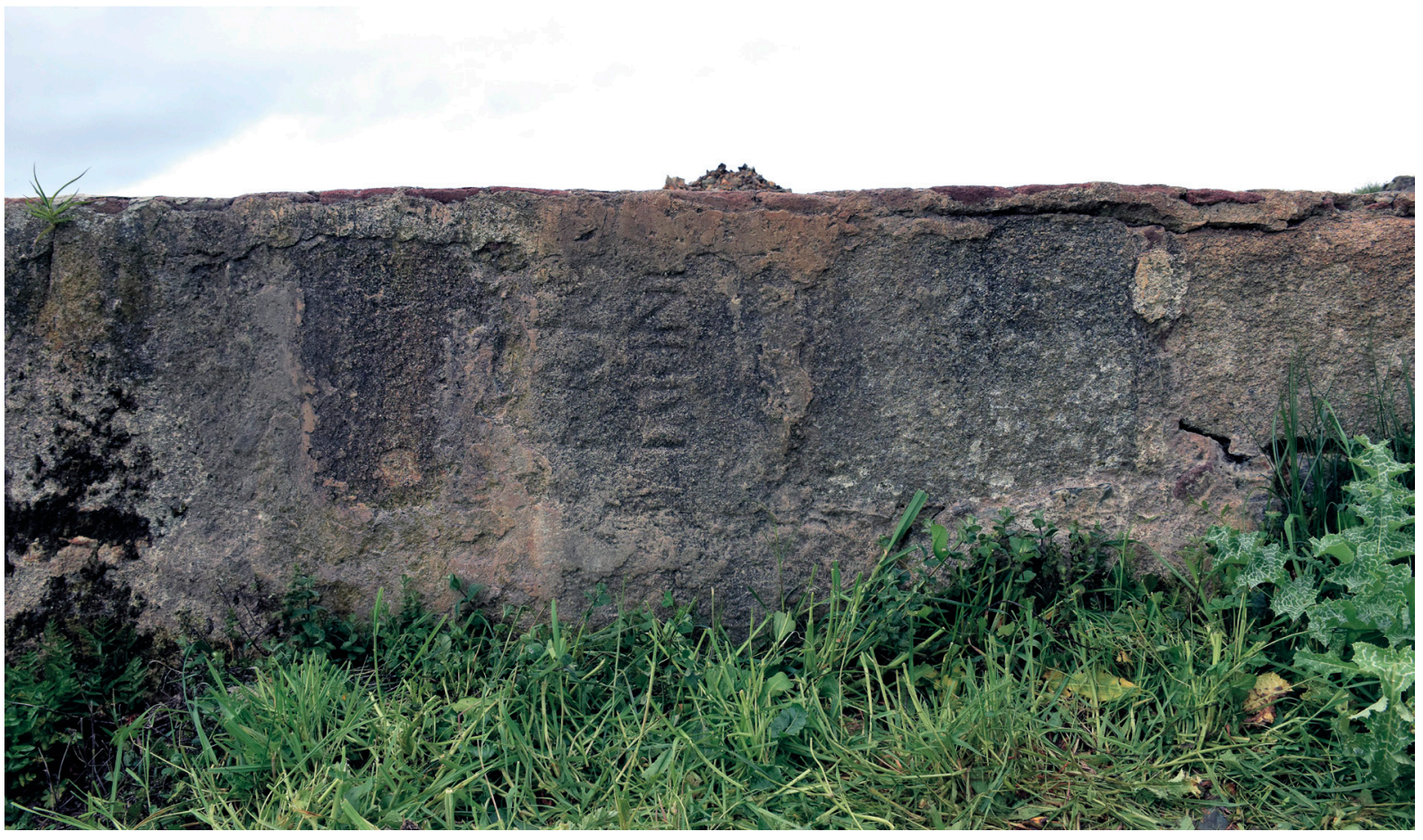

Figura 3. Epígrafe de El Cañuelo en su posición original. (Fotografía: R. Balbín-Bueno)

Figure 3. El Cañuelo epigraph in its original position. (Photograph: R. Balbín-Bueno) 


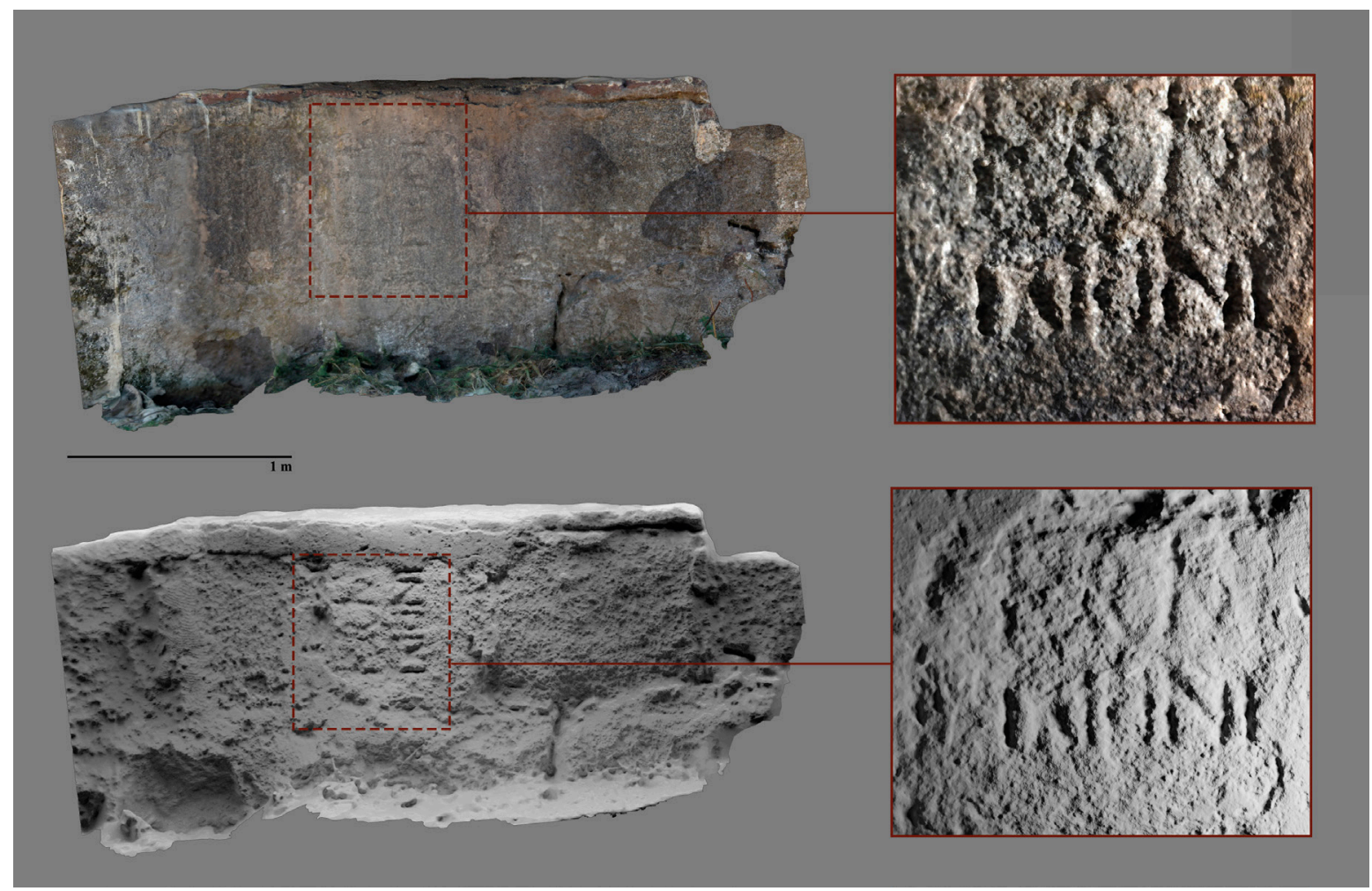

Figura 4. Reconstrucción fotogramétrica y modelado digital del epígrafe. (Tratamiento y montaje: C. Lapuente) Figure 4. Epigraph digital modelling and photogrammetric reconstruction. (Montage and editing: C. Lapuente)

Parece que el texto estaba en dos líneas, porque no hay restos de una tercera y, además, el comienzo LIS de la segunda indica que en la primera se grabó AVGVSTA.

Así las cosas, hay que calcular que, como cinco letras (TERMI) ocupan $47 \mathrm{~cm}$ las once que fal$\tan$ (NVS AVGVSTA) medirían casi un metro, por lo que el terminus original pudo medir $150 \mathrm{~cm}$ de ancho. Si la posible altura hoy conservada $(40 \mathrm{~cm})$ fuese la que tuvo, tendría una posición horizontal, mientras que el ya conocido (HEp 5, I995, II5) mide $100 \times 60 \mathrm{~cm}$ y estaba en posición vertical. Esta diferente posición podría explicar la diferencia de medida de las letras: las del antiguo, que se verían casi a la altura de los ojos, miden 5,5/6 cm mientras que las del nuevo miden $9 \mathrm{~cm}$. Naturalmente, al estar casi a ras de suelo se necesita un módulo mayor para que sean visibles y legibles. Sin embargo, desconocemos su posible altura, por lo que es posible que fuera similar al de Solaparza.

Si esta propuesta es válida, habría que admitir que el cipo granítico fue serrado y solo conservamos, en el mejor de los casos, un tercio del original: cosa extraña, pero es lo más que se puede decir sin realizar una intervención que supusiera la extracción del epígrafe de la fuente o, al menos, el desmontaje de parte de ella, soluciones en ambos casos controvertidas, ya que se trata de un bien histórico documentado en el mismo texto de Madoz que cita al terminus de Solaparza.

\section{El espacio delimitado por ambos termini}

Este nuevo terminus se ubica a algo más de $3 \mathrm{ki}-$ lómetros al sur de los Altos de Solaparza y, como en el caso anterior, en las inmediaciones del límite del manchón de tierras fértiles que caracterizan este tramo del Bodión en su margen izquierda y que se extiende por los términos de Fuente de Cantos y Valencia del Ventoso. En Solaparza hay actualmente un vértice geodésico, prueba del carácter delimitativo que tiene el lugar: debajo queda el valle que se adjudicó a los emeritenses. El nuevo terminus delimitaría la extensión occidental de la prefectura. 


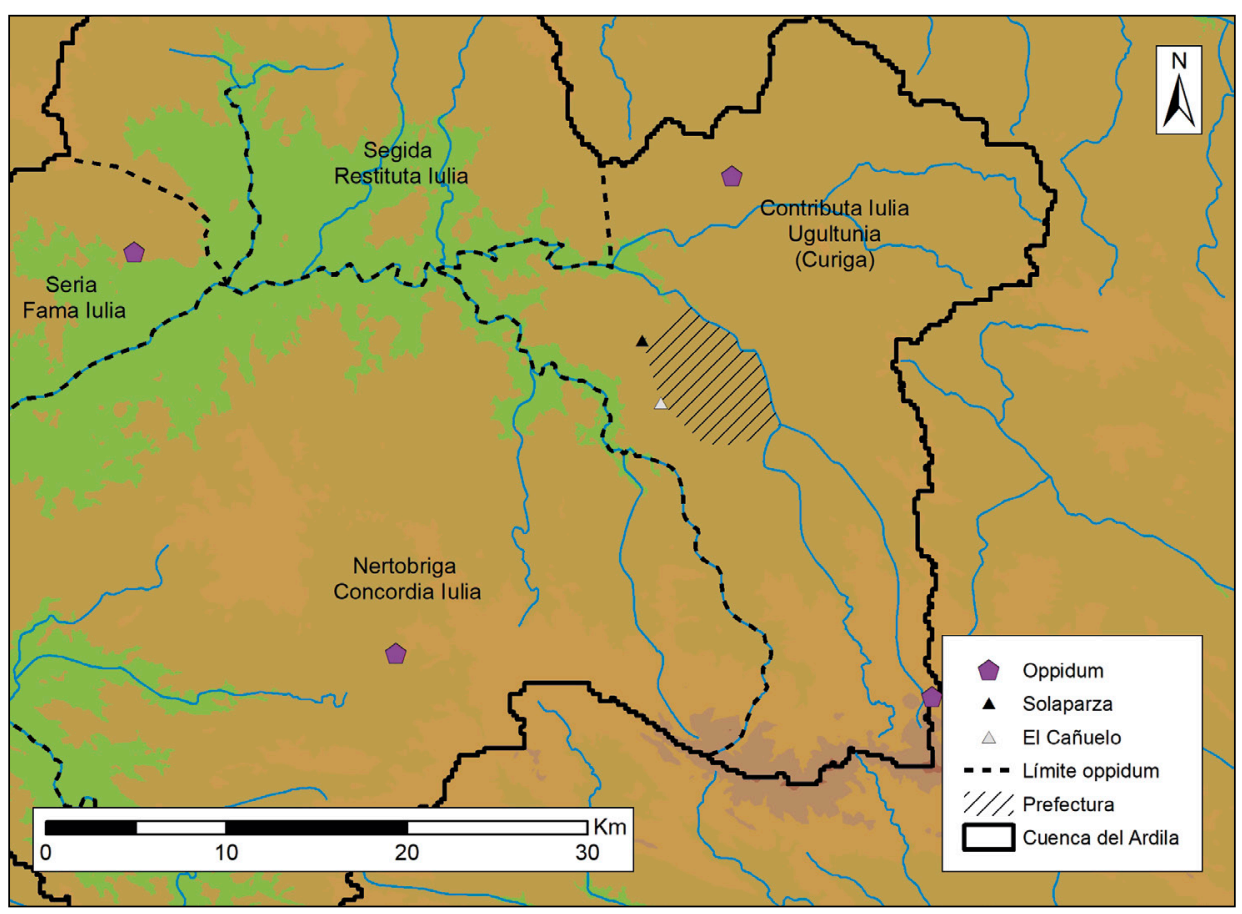

Figura 5. Mapa de localización de la Prefectura dentro de la cuenca del Ardila

Figure 5. Praefectura localization map within river Ardila basin

Por lo tanto, tendríamos definidos dos puntos liminales de la prefectura gracias a los dos termini documentados. Esta sería un enclave dentro de los territorios de las betúricas Ugultunia y Curiga, cuyos agri formaron durante un tiempo parte del mismo municipium: Contributa Iulia Ugultunia ${ }^{3}$. Según la extensión del resto de entidades y de la misma prefectura, quizá también lindase con Nertobriga y/o Segida (figura 5).

La razón de esta unidad administrativa dependiente de Lusitania, pero enclavada en territorio bético, creemos que se debe buscar en el mencionado manchón de tierras arcillosas de origen terciario, por lo que estaría vinculada con la producción agríco1a. Ello se relacionaría con la hipótesis de M. Alba (2018: I22) sobre la elección de Mérida como sede para los colonos augustanos por su capacidad para convertirse en un centro productor de avituallamiento

3 El hito de Solaparza ha sido considerado tanto augusteo como flavio, aunque sin ninguna evidencia que avale ninguna de las dos propuestas (Cortés Bárcena, 2013: 77); ello condiciona el territorio en el que se inserta ya que Curiga debió lograr su autonomía política durante el gobierno de Vespasiano (Fear, I99I: I6I). para el ejército. Sin embargo, cabe preguntarse por la necesidad de otorgar más tierras fértiles fuera del ager, cuando no se llegaron a repartir todas la de la pertica (Frontino, Th., 9; Agenio Úrbico, Th., 44), aunque se sabe que primero fueron distribuidas las más alejadas (Agenio Úrbico, Th., 44), por lo que, quizá también, fuesen repartidas en un primer momento las correspondientes a la prefectura como territorio más lejano de la colonia. Ariño y Gurt (1994: 46-47) ahondan en esta problemática y sostienen que la creación de las prefecturas no responde a cuestiones económicas, pues no se llegaron a agotar las tierras a distribuir, y buscan la respuesta en razones políticas, planteando que fueran represalias políticas. Sin embargo, para el caso tratado, Roma ha generado desde el principio un espacio político adaptado a sus necesidades pues todas las ciudades implicadas, tanto en la Bética como en la Lusitania, son fundaciones suyas, por lo que no se puede entender como un castigo a los oppida la inclusión de una prefectura aquí.

Puede parecer sorprendente que, hasta este momento, no se ha hallado ninguna inscripción en el espacio ocupado por esta prefectura (señalado en el mapa con líneas oblicuas). En cambio, se conocen 


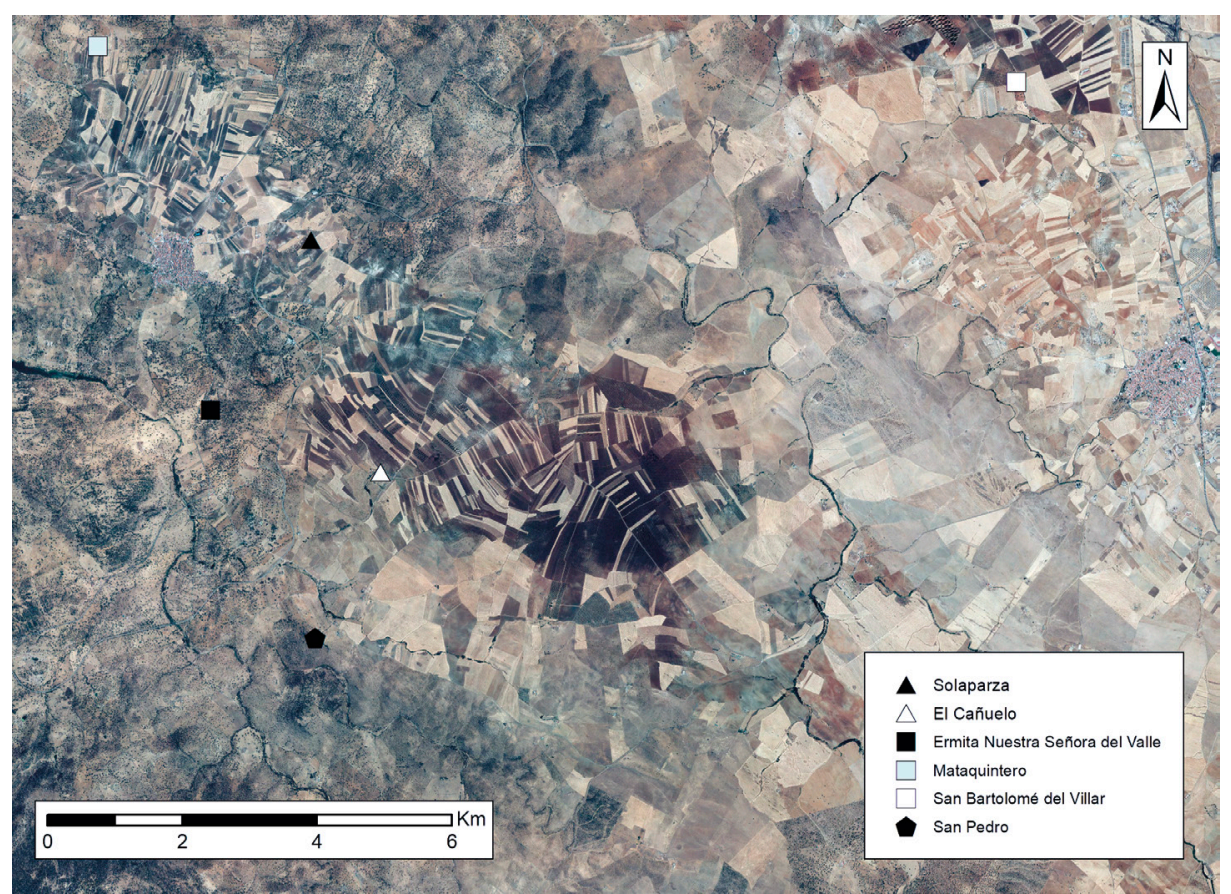

Figura 6. Localización de los termini y otros epígrafes circundantes sobre Ortofoto del PNOA de máxima actualidad del IGN

Figure 6. Termini and other surrounding epigraphs localization over an IGN very latest PNOA orthopohoto

inscripciones de los parajes de Mataquintero, ermita de Nuestra Señora del Valle, Cerro de San Pedro, San Bartolomé del Villar (ya en término de Fuente de Cantos y manifiestamente contributense, adscrito a la tribu Galeria) y La Gallega (también de Fuente de Cantos) $)^{4}$, cuya ubicación puede verse en el mapa siguiente. Son parajes, algunos próximos y otros más lejanos, pero fuera del espacio delimitado por los termini (figura 6).

Sin embargo, dentro del área delimitada por el Bodión y los termini sí se conocen ocupaciones humanas como los restos de mosaicos hoy desaparecidos (figura 7), fechados en los siglos III-IV d. C. (Gómez Rodríguez, I986: 48), en el lugar donde se ha propuesto la existencia de una villa (Prada, 2007: II4-II6), además de varios hábitats rurales (Calero et alii, e.p.). Evidentemente, una excavación sistemática del área donde aparecieron los mosaicos, a un centenar de metros del lugar donde se encuentra el epígrafe estudiado,

4 Inscripciones, debidamente actualizadas y latinizadas, entregadas en 20I3 para su revisión y reedición del CIL II, Conventus Hispalensis, Norte.

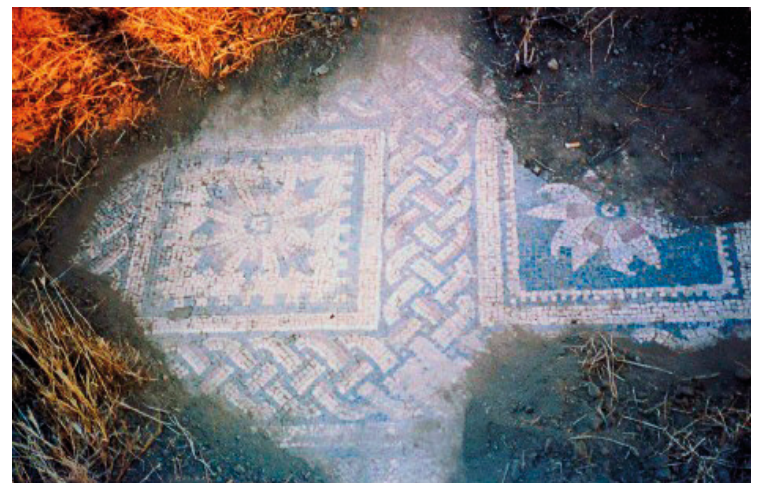

Figura 7. Fotografía del mosaico de El Cañuelo, hoy desparecido. (Fotografía: M.A. Vera)

Figure 7. Photograph of El Cañuelo mosaic, currently lost. (Photograph: M.A. Vera)

podría proporcionar materiales que colmataran la penuria de conocimientos que tenemos. Pero, en todo caso, los termini son suficientemente expresivos para localizar una de las prefecturas emeritenses.

\section{Reflexión final}

Esta inscripción, a pesar de su texto incompleto, parece tratarse de un terminus augustalis, cuyo contenido 
es similar al que ya se conocía y que se conserva en el MAP de Badajoz (HEp 5, I995, II5). Esto supone un notable avance en el conocimiento arqueológico de la zona, pues no se había producido ningún hallazgo epigráfico desde aquel, en el siglo xix, que aumentase el registro relacionado con los límites meridionales del territorio de Augusta Emerita.

Aunque hemos de mostrarnos cautos, dada la parquedad de datos con los que contamos, es probable que ambos termini delimitasen dos puntos cardinales del ager emeritensium, cuyo espacio coincide con un terreno fértil a orillas del río Bodión, en los municipios actuales de Valencia del Ventoso y Fuente de Cantos. Su ubicación, $20 \mathrm{~km}$ al sur de Los Santos de Maimona, donde comienza la jurisdicción de Contributa Iulia Ugultunia, y, a su vez, casi

\section{Bibliografía}

AE: L'Année épigraphique, revue des publications épigraphiques relatives à l'Antiquité romaine. Paris.

Alba Calzado, M. (2018): “Augusta Emerita, una puerta en Lusitania para suministro del ejército". En T. Nogales Barrasate y N. Barrero Martín (coords.): La fundación de Augusta Emerita y los orígenes de la Lusitania. MNAR. Mérida: II3-I48.

Ariño Gil, E. y Gurt, J.M. (1994): "Catastros romanos en el entorno de Augusta Emerita: Fuentes literarias y documentación arqueológica." En J.-G. Gorges y M. Salinas de Frías (eds.), Les Campagnes de Lusitanie romaine: occupation $d u$ sol et habitats. Madrid-Salamanca: 45-66.

Berrocal-Rangel, L. (2004): "El control de los caminos como recurso: el entramado viario de la Beturia Celtica”. En J.-G. Gorges, E. Cerrillo Martín de Cáceres y T. Nogales Basarrate (eds.): $V$ Mesa Redonda Internacional sobre Lusitania Romana: Las Comunicaciones. Madrid: I49-I75.

Calero Carretero, J.A., Carmona Barrero,J.D. y Guillén Vázquez, N. (e.p.): “Aproximación arqueológica a la ermita de San Pedro de Valencia del Ventoso: una hipótesis sobre su construcción". En C. Moreno Amador y A. Delgado Méndez (coords.), Patrimonio cultural en la Mancomunidad Rio Bodión: Pasado y Presente. Badajoz. colindante con Nertobriga Concordia Iulia y, quizá, Segida Restituta Iulia, solo puede explicarse por ser los termini de una de las tres prefecturas emeritenses, la cual no podemos identificar con la Mullicensis con los datos actualmente disponibles.

\section{Agradecimientos}

Expresamos nuestro agradecimiento a Helena Gimeno por las aportaciones realizadas al estudio de la pieza, así como a Ricardo Balbín-Bueno por la fotografía de la misma y a María de los Ángeles Vera por la del mosaico desaparecido de El Cañuelo. De igual manera, damos las gracias a Carlota Lapuente por el tratamiento digital realizado al cipo.

Canto de Gregorio, A.M. (1977-I978): "Avances sobre la explotación del mármol en la España romana". Archivo Español de Arqueología, 50-51: I65-187.

Canto de Gregorio, A.M. (1989): "Colonia Iulia Augusta Emerita: Consideraciones en torno a su fundación y territorio". Gerión, 7: 149-205.

Canto de Gregorio, A.M. (1997): Epigrafía Romana de la Beturia Céltica (E.R.B.C.). Universidad Autónoma de Madrid. Madrid.

Cordero Ruiz, T. (2010): "Una nueva propuesta sobre el ager emeritensis durante el Imperio Romano y la Antigüedad Tardía”. Zephyrus, 65: I49-165.

Cordero Ruiz, T. (2013): El territorio emeritense durante la Antigüedad Tardía (siglos IV-VIII). Génesis $y$ evolución del mundo rural lusitano. Anejos de Archivo Español de Arqueología, LXVI. Mérida.

Cortés Bárcena, C. (2013): Epigrafía en los confines de las ciudades romanas. Los termini publici en Hispania, Mauretania y Numidida. L'Erma di Bretschneider. Roma

Fear, A.T. (199I): "Contributa lulia, Ugultunia and Curiga”. Gerión, 9: 15I-16r.

García-Bellido, M.P. (200I): "Lucus Feroniae Emeritensis". Archivo Español de Arqueología, 74: 53-71.

García Iglesias, L. (197I): "La Beturia. Un problema geográfico de la Hispania Antigua". Archivo Español de Arqueología, 44: 86-108. 
Gimeno Pascual, H. y Ramírez Sádaba, J.L. (1998): "Nuevos testimonios arqueológicos y epigráficos de Medina de las Torres (Badajoz), en un manuscrito inédito del siglo XIX". SPAL, 7: I49-I62.

Gómez Rodríguez, M. (I986): Urbanismo y arte en Valencia del Ventoso. Tesis de licenciatura inédita. Universidad de Extremadura. Cáceres.

González Fernández, J. (1996): "Mansio Mons Mariorum (It. Ant. 432.4)”. Habis, 27: 83-96.

HEp: Hispania Epigraphica, revista del Archivo Epigráfico de Hispania, Universidad Complutense de Madrid.

Kerner, A. (2013): Studien zur Geschichte von Augusta Emerita im I. und frühen 2. Jh. n. Chr. PhilippsUniversität Marburg. Marburg.

Madoz, P. (1849): Diccionario geográfico-estadísticohistórico de España y sus posesiones de ultramar. Libro XV. Madrid.
Prada Gallardo, A. (2007): Arqueología de las comarcas del suroeste de Badajoz: Valencia del Ventoso y Fregenal de la Sierra. Aqualia. Badajoz.

Ramírez Sádaba, J.L. (1993): "Dos termini augustales del territorium emeritense: uno de Valencia del Ventoso y otro de Montemolín”. Veleia, ro: 30I-305.

Rodríguez Martín, F.G. (2008-2009) "Las vías romanas de Lusitania: el trazado en el Conventus Emeritense y su proyección hacia la fachada atlántica”. Anas, 2I-22: 415-469.

Salas Martín, J., Esteban Ortega, J., Redondo Rodríguez,J.A.y Sánchez Abal, J.L. (1997): Inscripciones romanas y cristianas del Museo Arqueológico Provincial de Badajoz. Museo Arqueológico Provincial de Badajoz. Badajoz.

Thulin, C. (trad.) (1913): Corpus agrimensorum romanorum. Opuscula agrimensorum veterum. Stuttgart. 